\title{
Effect of milk deprivation during the lactation period on performance and digestive enzyme activities of the piglets following weaning
}

\author{
W. Wattanakul ${ }^{1,2 \dagger}$, J. A. Rooke ${ }^{1 \neq}$, A. H. Stewart ${ }^{1 \S}$, P. R. English ${ }^{2}$ and S. A. Edwards ${ }^{1 \|}$ \\ ${ }^{1}$ Scottish Agriculture College, Craibstone Estate, Aberdeen AB21 9YA, UK; ${ }^{2}$ University of Aberdeen, 581 King Street, Aberdeen AB24 5UA, UK
}

(Received 12 July 2006; Accepted 4 December 2006)

Post-weaning performance of piglets from systems where lactation is disrupted (e.g. from multisuckling systems) is superior to conventionally reared piglets. The objective of this study was to establish whether restricted growth prior to weaning caused by disruption of suckling was an important factor in post-weaning performance and also whether there were related changes in gastro-intestinal development. Ten litters of eight piglets were used in a split-plot design. Half of each litter (limited suckling, LS) had suckling disrupted by separation from their dam for $7 \mathrm{~h} /$ day from day 14 to 28 after farrowing. The remainder of each litter was allowed to suck normally (normal suckling, NS). The same amount of creep feed was offered to LS piglets as consumed by NS littermates on the previous day. There were no differences in weight between LS and NS piglets at 14 days of age, but restricting access to the sow reduced weaning weight at 28 days of age (7.96 v. $9.00 \mathrm{~kg}$; LS v. NS; P < 0.01; s.e.d. 0.23). Feed intakes were greater for $L S$ than NS piglets over the first 28 days post weaning, particularly in the 1st week after weaning when feed efficiency was also improved (0.91 v. $0.62 \mathrm{~kg}$ gain per $\mathrm{kg}$ feed; $\mathrm{P}<0.01$; s.e.d. 0.08 ). As a result, LS piglets grew more rapidly in the first 28 days post weaning, particularly in the first 7 days after weaning. Subsequent performance to 8 weeks was similar for both groups. Digestive organ weights were not different at 2 and 9 days after weaning; nor were small intestine specific enzyme activities significantly different $(P>0.05)$. Pancreatic trypsin activity was, however, greater $(P<0.01)$ for $L S$ pigs on both days 2 and 9 post weaning. In conclusion the restriction of growth as a result of limited suckling itself is an important factor in determining post-weaning performance and may be related to development of pancreatic trypsin activity.

Keywords: digestive enzyme activity, lactation, milk deprivation, piglets, weaning

\section{Introduction}

Piglets raised in lactation systems which involve grouping sows and piglets in loose housing with straw bedding (multi-suckling systems) were lighter at weaning than contemporary conventionally reared piglets as a result of disrupted suckling after mixing (Hatet et al., 1994; Wattanakul et al., 1997a). However, piglets from multi-suckling systems had higher feed intakes and growth rates following weaning compared with conventionally weaned pigs. Piglets that are prematurely weaned due to maternal desertion, as observed in the sow-controlled loose farrowing system (Bøe, 1993;

\footnotetext{
${ }^{\dagger}$ Present address. Faculty of Agriculture, Ubonratchathani University, Thailand, 34190. E-mail: w.wattanakul@rocketmail.com

${ }^{\ddagger}$ Present address. SAC, Roslin Bio-Centre, Roslin, Midlothian EH25 9PS, UK

${ }^{\S}$ Present address. Harper Adams University College, Newport, Shropshire TF10 $8 N B, U K$.

"Present address. School of Agriculture, Food and Rural Development, University of Newcastle, Newcastle upon Tyne NE1 7RU, UK.
}

Rantzer et al., 1995a and b), or small piglets which have already compensated behaviourally in the farrowing house for inadequate milk intake (Algers et al., 1990) exhibit similar enhanced feed intake and live-weight gain after weaning. In both these examples piglets increased creep feed intake during the lactation period. However, this was not the case for multi-suckling piglets who did not increase creep feed intake (Wattanakul et al., 1997a). Reduced aggression after weaning because piglets are familiar through previous co-mingling (Wattanakul et al., 1997b) or by being weaned from more enriched environments (Beattie et al., 1995) have been suggested as reasons for some of the improved performance when piglets are weaned from multisuckling systems.

It was the objective of this experiment to assess the role of pre-weaning growth restriction resulting from disruption of suckling in isolation from these other possible influences on post-weaning performance. The experiment 
was designed to avoid both differences between the preweaning multi-suckling and conventional farrowing crate environments and to ensure that the stress of being mixed following weaning did not differ between experimental groups. Thus it was hypothesised that it was milk deprivation prior to weaning, rather than other environmental circumstances, that was responsible for piglets showing increased feed intake and live-weight gain following weaning. The post-weaning development of digestive organs and enzyme activities were also quantified to establish if one consequence of milk deprivation was changes in ontogeny of digestive enzymes.

\section{Materials and methods}

\section{Experimental procedures}

The experiment was conducted according to a split-plot design. Each litter was arranged as a main plot to reduce the effect of sow on piglet performance, and treatments were allocated to piglets within litter as a subplot. In total, 80 piglets from 10 sows (Large White $\times$ Landrace) were employed in this study. Seven days after farrowing, the size of each litter was reduced to eight piglets to avoid fostering-on effects and inclusion of individuals of extreme weight. Pelleted creep feed was weighed and provided ad libitum in a hopper from days 7 to 14 after farrowing. From day 14, access to creep feed was restricted to $7 \mathrm{~h} /$ day.

At day 14 after farrowing, the piglets in each litter were allocated on the basis of body weight into two groups of four piglets. The 40 piglets from the first five replicates (litters) were used in a performance study until 8 weeks after weaning. The other 40 piglets from the second five replicates were used in a digestive enzyme development study which was terminated 9 days after weaning.

From day 14 until weaning at 28 days of age, four piglets from each litter were allowed full and continuous access to the sows (NS), whilst the other four piglets were prevented from sucking (LS) for $7 \mathrm{~h} /$ day by being removed to a nursery area between 0830 and $1530 \mathrm{~h}$. The four LS piglets from each litter were grouped together with an allowance of $0.25 \mathrm{~m}^{2}$ per piglet. Water was supplied ad libitum and creep feed (composition, per kg; crude protein (CP), $230 \mathrm{~g}$; oil, $130 \mathrm{~g}$; lysine, $17 \mathrm{~g}$; digestible energy (DE) $16.5 \mathrm{MJ}$ ) was provided for both groups during the 7 -h daily separation period, with the LS group being offered the same amount of creep feed as consumed by their NS littermates on the previous day. The period of suckling deprivation was calculated to give a reduction in milk energy intake appropriate to give a reduction in the growth rate of LS piglets similar to that recorded in the previous multisuckling experiment of Wattanakul et al. (1997a) (68.5 g of growth per day or $0.96 \mathrm{~kg}$ for 2 weeks).

After weaning, all piglets were housed for 4 weeks in flat-deck accommodation. The four piglets from each litter subgroup were grouped together in a pen. For weeks 5 to
8 after weaning, the same groups of piglets were transferred to second stage pens. Water was provided ad libitum to all groups. Composition of feeds offered to the piglets were as follows: from days 28 to 35 , creep feed, composition as above; days 35 to 56 (per $\mathrm{kg}$ ); $\mathrm{CP}, 230 \mathrm{~g}$; oil, $90 \mathrm{~g}$; lysine, $17 \mathrm{~g} ; \mathrm{DE}, 16.5 \mathrm{MJ}$; from days 56 to 84 (per $\mathrm{kg}$ ); $C P, 220 \mathrm{~g} ;$ oil, $45 \mathrm{~g}$; lysine, $15 \mathrm{~g}$; DE, $14.3 \mathrm{MJ}$. Piglet body weight was recorded weekly. Feed intake was recorded daily from 14 days after farrowing until 1 week after weaning, weekly from 1 to 4 weeks after weaning and every 2 weeks from weeks 5 to 8 after weaning.

On days 2 and 9 after weaning, the piglet from each treatment group whose weight was closest to the group mean was sacrificed for enzyme analyses ( 5 piglets per time per treatment; 20 piglets in total). The remaining 20 piglets were released from the experiment at 9 days after weaning.

\section{Post mortem procedure}

To standardise the degree of gut fill and recent ingestive history, piglets to be sacrificed were fasted in an individual pen for $15 \mathrm{~h}$ overnight with water ad libitum prior to slaughter. The piglets were killed by an overdose of sodium pentobarbital (Euthatal) administered intra-peritoneally. The abdominal cavity was opened, the gastro-intestinal tract ligatured at the pyloric valve and ileo-ceacal junction and the entire gastro-intestinal tract removed. The pancreas was also removed and weighed. The stomach was opened and weighed after washing out its contents. The small intestine was removed, and weighed after washing gently with saline $(9 \mathrm{~g} \mathrm{NaCl} / \mathrm{l})$. Duplicate samples of small intestine were obtained from sites $0.25,0.50$ and 0.75 along the gut from the gastric pylorus to the ileoceacal valve by distance (referred to as sites 1, 2 and 3). The pancreas and samples of small intestine were snap frozen in liquid nitrogen and stored at $-70^{\circ} \mathrm{C}$ until subsequent analysis. Total processing time from death to obtaining gut samples was about $20 \mathrm{~min}$.

\section{Sample preparation and enzyme analysis}

The methods used for sample preparation were adapted from Chapple et al. (1989). The frozen small intestine segments and pancreas were thawed on crushed ice, and the mucosa gently scraped off with a spatula. The mucosa was then homogenised $(1: 10 \mathrm{w} / \mathrm{v})$ for $1 \mathrm{~min}$ in water at 2000 r.p.m. in a homogeniser (model D-7801 Dottingen type $\mathrm{X} 1020)$. The homogenates were centrifuged at $500 \mathrm{~g}$ at $4^{\circ} \mathrm{C}$ for $10 \mathrm{~min}$ to remove cellular debris and connective tissue. The supernatants were then stored at $-70^{\circ} \mathrm{C}$. The pancreas was thawed on ice and chopped. A sample of $1.0 \mathrm{~g}$ was homogenised as above with $10 \mathrm{ml}$ of distilled water. Homogenisation and centrifugation were carried out as in the small intestine preparation.

Sucrase, maltase and lactase activities in the small intestine were determined according to Messer and Dahlqvist (1966) in 96-well plates and optical density (OD) measured at $492 \mathrm{~nm}$ (reference wavelength, $650 \mathrm{~nm}$ ) using a Behring 
ELISA processor II. Amino peptidase activity in mucosal homogenates of the small intestine was determined using L-alanine-p-nitroanilide as substrate at $405 \mathrm{~nm}$ (Maroux et al., 1973).

Trypsin and chymotrypsin activities in pancreatic tissue were measured after activation (Glazer and Sterr, 1976) by a modification of Nitsan and Liener (1976). The enzyme activities were assayed in 96-well plates using as substrates $0.4 \mathrm{~g} / \mathrm{l} \mathrm{N}$-benzoyl-DL-arginine-p-nitroanilide for trypsin (Erlanger et al., 1961) and $0.4 \mathrm{~g} / \mathrm{l} \mathrm{N}$-glutaryl-Lphenylalanine-p-nitroanalide for chymotrypsin (Erlanger et al., 1966). Optical density was measured at $405 \mathrm{~nm}$ (reference wavelength $650 \mathrm{~nm}$ ). Protein concentration was determined in homogenates of intestinal mucosa and pancreas according to Lowry et al. (1951) using bovine serum albumin as the standard.

\section{Statistical analysis}

For analysis of data from the farrowing house stage and from the 1st week post weaning, data on performance from piglets in both the performance study and gastrointestinal study groups were pooled. Data for live weight, feed intake, feed conversion efficiency, digestive tract weights and pancreatic enzyme activities were analysed using a repeated measures analysis of variance using Genstat (Lawes Agricultural Trust, 1988) with weaning weight used as a covariate where significant. Within the analysis, each litter was a main plot and treatment within litter was a subplot. Effects of time were assessed using linear and quadratic polynomials. Differences between LN and NS treatments over time were identified as interactions between treatment and linear or quadratic polynomial. The enzyme activities in the small intestine, were analysed according to a split-plot design using Genstat software ${ }^{\circledR}$ (Lawes Agricultural Trust, 1988). Suckling treatment and age at sampling were main plot factors analysed at a litter level, with sampling site treated as a subplot. Carcass and weaning weight were tested as possible covariates, but had no significant effect on the analysis. Therefore, the analysis was performed without using a covariate. Comparison between treatments was made by calculating the standard error of difference (s.e.d.) and least significant difference (LSD).

\section{Results}

\section{Performance results}

Between days 70 and 84 of age, one piglet in the performance study suffered from severe enzootic pneumonia; the performance data from this piglet were therefore excluded.

At allocation to treatments at 14 days of age, there were no differences in weight between $L S$ and NS piglets (4.78 v. $4.80 \mathrm{~kg}$; LS v. NS; s.e.d. 0.04). As planned, restricting access to the sow (LS) reduced weaning weight at 28 days of age when compared with piglets (NS) with unrestricted access to the udder $(7.96$ v. $9.00 \mathrm{~kg}$; LS v. NS;
$P<0.01$; s.e.d. 0.23 ). During the suckling period, piglets showed little interest in creep feed. Creep feed intakes from days 14 to 28 after farrowing were only 1.2 and $1.5 \mathrm{~g}$ per pig per week (LS v. NS; s.e.d. 0.33; $P>0.05$ ).

Overall there were no differences (LS $v$. NS) in liveweight gain $(521$ v. $516 \mathrm{~g} /$ day, s.e.d. 36.4$)$ or feed intake (803 v. $802 \mathrm{~g} /$ day, s.e.d. 39.0 ) between 28 and 84 days of age. However, there were differences between groups in the pattern of feed intake and live-weight gain between 28 and 84 days of age. Feed intakes were greater for LS than NS piglets over the first 28 days post weaning, particularly in the 1st week after weaning (Figure 1; linear time $\times$ treatment interaction, $P=0.024$ ). As a result $L S$ piglets grew more rapidly in the first 28 days post weaning; again this effect was most marked in the first 7 days after weaning (Figure 2; linear time $\times$ treatment interaction, $P=0.016)$. As a result, the difference in weaning weight between treatments was abolished within 2 weeks (42 day weight 12.35 v. $12.19 \mathrm{~kg}$; s.e.d. 0.44 ). The superior feed intake in the first 7 days after weaning $(P<0.001$; Figure 3 ) arose as a result of consistently increased daily intakes from the 1st day post weaning. The apparent efficiency of feed utilisation was also superior for LS piglets during this $1 \mathrm{st}$ week $(0.91$ v. $0.62 \mathrm{~kg}$ gain per $\mathrm{kg}$ feed; $P<0.01$; s.e.d. 0.08$)$

\section{Digestive organ weights and enzyme activities}

There were no significant differences $(P>0.05)$ between NS and LS piglets at 2 or 9 days after weaning in digestive organ weights or small intestine length, whether expressed as absolute values (Table 1) or per $\mathrm{kg}$ body weight (data not shown).

Total organ weights, defined as the difference between body weight and carcass weight, of NS piglets were significantly higher than for LS $(1.62$ v. $1.29 \mathrm{~kg}$, s.e.d. 0.089 ,

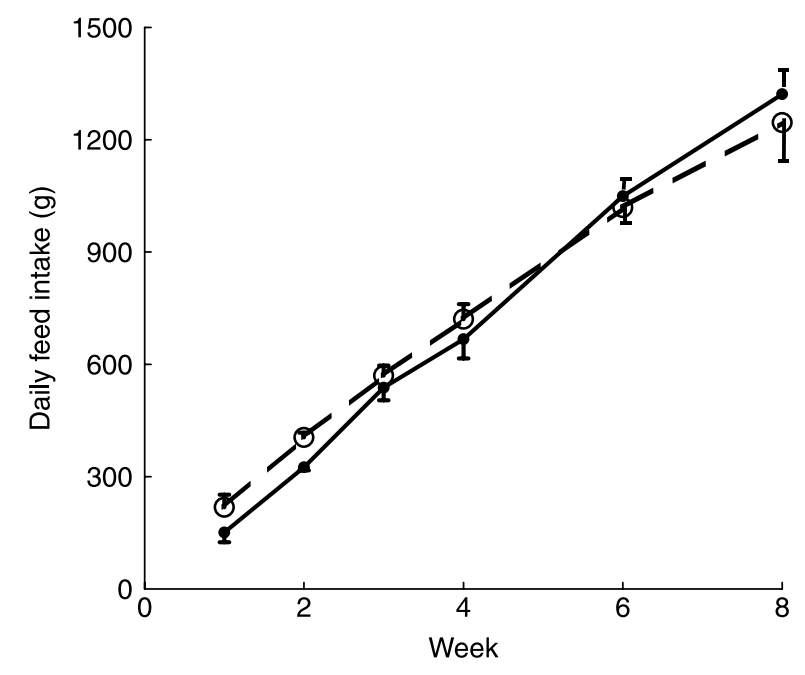

Figure 1 Mean (with s.e.) weekly feed intakes of piglets who were allowed to suck the sow normally from days 14 to 28 of age (NS, - o ) or had restricted access to the sow (LS,O---O) from weaning at 28 days of age until 12 weeks of age. Standard error of difference for five pens per treatment, 56.0. 


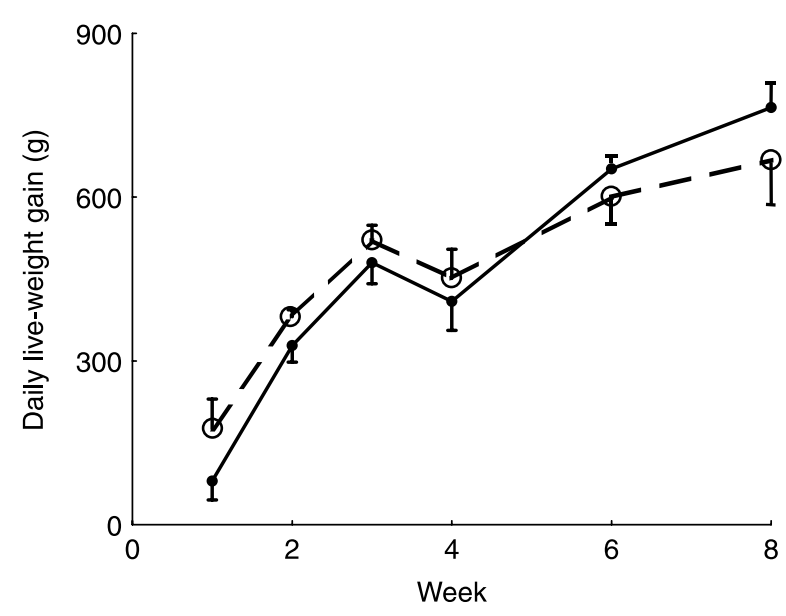

Figure 2 Mean (with s.e.) weekly weight gains of piglets who were allowed to suck the sow normally from days 14 to 28 of age (NS, - ) or had restricted access to the sow (LS, O---O) from weaning at 28 days of age until 12 weeks of age. Standard error of difference for five pens per treatment, 0.85 .

$P<0.05) 2$ days after weaning, but this difference partially reflected differences in body weight (organ weight expressed per $\mathrm{kg}$ body weight was 0.201 v. $0.184 \mathrm{~kg} / \mathrm{kg}$, s.e.d. 0.0134, $P>0.05$ ). Small intestines of NS piglets also tended to be heavier $(P=0.09)$ than LS piglets 2 days after weaning. However, the weight of intestinal organs increased more in LS than NS piglets between days 2 and 9 post weaning (NS v. LS; 136.9 v. 202.9 g, s.e.d. 11.59 , $P<0.01$ ) mainly from a greater increase in small intestine weights (NS v. LS; 112.6 v. 178.6 g, s.e.d. $8.14, P<0.01$ ) simply a reflection of live weight and live-weight change.

There were no differences in mucosal protein content at any site along the small intestine at either sampling time (Table 2). Two days after weaning, LS piglets had higher $(P<0.05)$ overall amino peptidase activities than NS

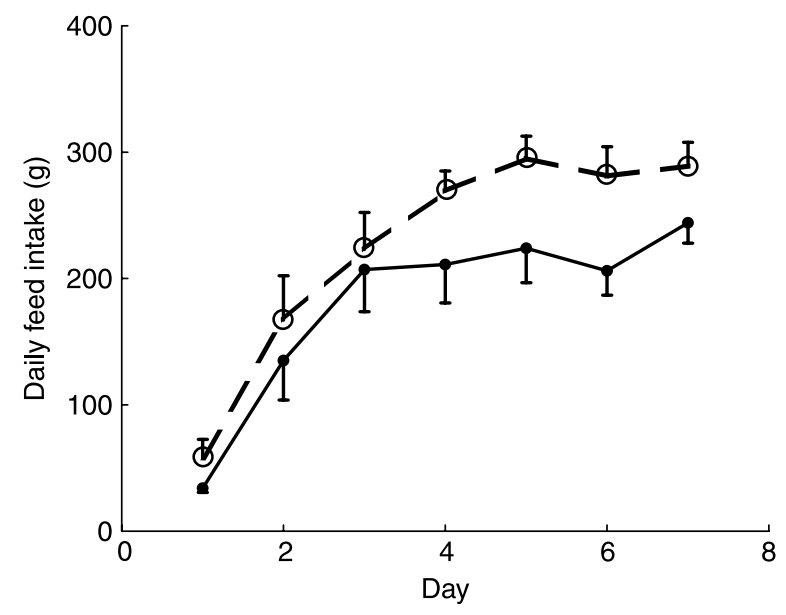

Figure 3 Mean (with s.e.) daily feed intakes of piglets who were allowed to suck the sow normally from days 14 to 28 of age (NS, _ restricted access to the sow ( $L S, O---O)$ from weaning at 28 days of age until 35 days of age. Standard error of difference for 10 pens per treatment, 25.8. piglets, largely caused by differences at site $3(P<0.01)$. Amino peptidase activities in LS piglets were lower $(P<0.05)$ at day 9 than at day 2 post weaning; for NS piglets differences between sampling days were not significant $(P>0.05)$.

Sucrase and maltase activities did not differ between treatments at either sampling day. While maltase activity did not change between sampling day, sucrase activity was lower at day 9 than day 2 . The specific activity of lactase declined $(P<0.05)$ from day 2 to day 9 after weaning in both groups. However, there was no overall difference in lactase activity between treatments $(P>0.05)$.

Protein content of pancreatic tissue did not differ between treatments (Table 3; $P>0.05$ ). However, pancreatic trypsin activity was higher $(P<0.01)$ in LS piglets both 2 and 9 days after weaning; overall trypsin activity was greater at day 9 than day $2(P<0.01)$ after weaning. There were no $(P>0.05)$ differences in chymotrypsin activity between treatments.

\section{Discussion}

There were two main findings from this study. First, the use of an experimental model to re-create the reduced preweaning and increased post-weaning weight gains observed in multi-suckling studies (Wattanakul et al., 1997a) but with confounding factors minimised, was successful. Thus the increased post-weaning food intake and weight gain could be attributed directly to the restriction in suckling. Secondly there were accompanying changes in post-weaning pancreatic trypsin activity when suckling was restricted.

The model used removed three factors that could confound comparisons between conventional farrowing crates and multi-suckling systems. First, creep feed was equalised between LS and NS piglets by offering LS creep feed in amounts consumed by NS piglets the previous day. To differentiate between creep feed intakes of LS and NS piglets, creep feed could only be offered whilst the LS piglets were removed from the sow. This was probably the reason why creep feed intakes by NS piglets in this study were less than in other studies where suckling was restricted (Thompson et al., 1981; Chapple et al., 1989), or in the multi-suckling system (Wattanakul et al., 1997a) but was a necessary consequence of the model system used. In the current study, even though the amount of creep feed offered to the LS piglets was the same as the daily intake of NS piglets, a small and non-significant amount of creep feed was not consumed. Even when creep feed is presented ad libitum in the farrowing house, it has been noted that some piglets are not interested in creep feed (Appleby et al., 1991) and thus do not explore and learn to consume a source of nutrients other than milk. In the present experiment, the stress of being separated from their mother and the change to a new environment may have had an effect on the ability of LS piglets to learn to 
Milk deprivation and digestive enzyme activities of piglets

Table 1 Effect of normal (NS) or limited (LS) suckling on carcass weight, digestive organ weight and small intestine length at 2 and 9 days after weaning

\begin{tabular}{|c|c|c|c|c|c|c|c|c|}
\hline \multirow[b]{2}{*}{ Days after weaning } & \multicolumn{2}{|c|}{ Day 2} & \multicolumn{2}{|c|}{ Day 9} & \multirow[b]{2}{*}{ s.e.d. ${ }^{\dagger}$} & \multicolumn{3}{|c|}{ Significance } \\
\hline & NS & LS & NS & LS & & Treatment & Day & Interaction \\
\hline Body weight (kg) & 8.0 & 7.0 & 9.7 & 9.5 & 0.69 & & *** & \\
\hline Carcass weight (kg) & 6.4 & 5.8 & 7.6 & 7.3 & 0.58 & & *** & \\
\hline Stomach weight(g) & 44.1 & 41.4 & 63.8 & 59.6 & 5.48 & & *** & \\
\hline Small intestine weight (g) & 273 & 210 & 386 & 390 & 38.9 & & *** & * \\
\hline Pancreas weight $(\mathrm{g})$ & 14.1 & 11.7 & 18.7 & 17.9 & 2.30 & & ** & \\
\hline Small intestine length (m) & 9.0 & 8.3 & 10.2 & 10.1 & 0.44 & & *** & \\
\hline
\end{tabular}

${ }^{\dagger}$ s.e.d. of treatment $\times$ day $(n=5)$.

consume creep feed. However, the fact that creep feed intakes did not differ significantly between LS and NS piglets meant that creep feed intake and adaptation to novel foods was unlikely to be a contributory factor to the differences between LS and NS piglets. Another consequence of the experimental model was that by removing LS piglets from the sow, NS piglets may have been advantaged compared with piglets in a normal farrowing pen environment.

Table 2 Small intestine mucosal protein concentration and digestive enzyme specific activities of piglets allowed unrestricted suckling (NS) or limited suckling (LS) and killed 2 and 9 days after weaning

\begin{tabular}{|c|c|c|c|c|c|}
\hline & \multicolumn{4}{|c|}{ Days after weaning } & \multirow[b]{3}{*}{ s.e.d. } \\
\hline & \multicolumn{2}{|c|}{ Day 2} & \multicolumn{2}{|c|}{ Day 9} & \\
\hline & NS & LS & NS & LS & \\
\hline \multicolumn{6}{|c|}{ Mucosa protein (mg/g) } \\
\hline Site 1 & 93 & 93 & 80 & 83 & \\
\hline Site 2 & 79 & 84 & 82 & 89 & \\
\hline Site 3 & 82 & 82 & 85 & 87 & $4.5^{\dagger}$ \\
\hline Mean & 85 & 86 & 83 & 86 & 2.7 \\
\hline \multicolumn{6}{|c|}{ Amino peptidase ( $\mu \mathrm{mol} / \mathrm{min}$ per $\mathrm{g}$ protein) } \\
\hline Site 1 & 49 & 61 & 68 & 56 & \\
\hline Site 2 & 70 & 65 & 69 & 60 & \\
\hline Site 3 & $66^{\mathrm{b}}$ & $112^{\mathrm{a}}$ & $86^{\mathrm{b}}$ & $70^{\mathrm{b}}$ & $11.9^{\dagger}$ \\
\hline Mean & $61^{\mathrm{a}}$ & $79^{\mathrm{b}}$ & $74^{\mathrm{ab}}$ & $62^{\mathrm{a}}$ & 6.4 \\
\hline \multicolumn{6}{|c|}{ Sucrase ( $\mu$ moles/min per g protein) } \\
\hline Site 1 & 31 & 47 & 28 & 23 & \\
\hline Site 2 & 42 & 36 & 24 & 19 & \\
\hline Site 3 & 34 & 45 & 22 & 21 & $13.0^{\dagger}$ \\
\hline Mean & 35 & 43 & 25 & 21 & 11.5 \\
\hline \multicolumn{6}{|c|}{ Maltase ( $\mu$ moles/min per g protein) } \\
\hline Site 1 & 61 & 86 & 82 & 59 & \\
\hline Site 2 & 91 & 77 & 89 & 77 & \\
\hline Site 3 & 85 & 94 & 77 & 74 & $23.2^{\dagger}$ \\
\hline Mean & 79 & 86 & 83 & 70 & 18.7 \\
\hline \multicolumn{6}{|c|}{ Lactase ( $\mu \mathrm{mols} / \mathrm{min}$. per g protein) } \\
\hline Site 1 & $22^{\mathrm{a}}$ & $33^{\mathrm{a}}$ & $18^{a}$ & $12^{\mathrm{b}}$ & \\
\hline Site 2 & 22 & 21 & 11 & 7 & \\
\hline Site 3 & 12 & 14 & 3 & 3 & $6.0^{\dagger}$ \\
\hline Mean & $19^{b c}$ & $23^{c}$ & $10^{\mathrm{ab}}$ & $8^{a}$ & 4.8 \\
\hline
\end{tabular}

\footnotetext{
${ }^{\mathrm{a}, \mathrm{b}}$ Within rows, means not followed by a common superscript differ significantly $(P<0.05)$.

${ }^{\dagger}$ s.e.d. of treatment $\times$ site for all three sites.
}

To standardise the piglets used in the comparison litter sizes were reduced to eight, which in itself would have maximised available teats of good quality and thus reduced competition compared with more typical litter sizes.

The second difference between multi-suckling and conventional farrowing systems that was removed by using the current experimental design was mixing with unfamiliar piglets. In fact, this stressor was less than in many conventional systems since piglets were maintained in litter groups and not mixed with unfamiliar pigs at any stage of the experiment, as often occurs in commercial practice either at weaning or when moved from weaning to growing pig accommodation. Finally, except for the inevitable period during which piglets were removed from the sow to reduce suckling, LS and NS suckling piglets were exposed throughout the experiment to the same environmental conditions (pen design, degree of physical and social enrichment, temperature and humidity) that conformed to industry guidelines. The only environmental difference which might be implicated in the more rapid adaptation to solid food demonstrated by the LS piglets at weaning was therefore prior exposure to an environment where the sow was absent. However, the hypothesis that restriction of pre-weaning growth arising from reduction in suckling could result in increased feed intake after weaning was supported by the experimental results.

Measurements were made of small intestine and pancreatic weights and enzyme activities to assess whether any differences in animal performance could be related to differences in these measurements. There were in fact few differences in small intestinal measurements. The lack of change of aminopeptidase activity (Hedemann et al., 2003) and the decline in lactase specific activity (Cranwell, 1995) with time after weaning are in agreement with published data. Similarly, although the manner in which differences in weaning weight were achieved (present study, restricted suckling) the lack of any effect of weaning weight on small intestine enzyme activities was similar to the observations of Hedemann et al., 2003; piglets differing in birth weight and nutrition during lactation). The main difference as a result of weaning weight in the present experiment was the greater increase in small intestine weight between days 2 
Wattanakul, Rooke, Stewart, English and Edwards

Table 3 Pancreatic tissue protein concentration (mg/g tissue) of and specific trypsin and chymotrypsin activities ( $\mu \mathrm{mol} / \mathrm{min} \mathrm{per} g \mathrm{protein}$ ) of piglets allowed unrestricted suckling (NS) or limited suckling (LS) and killed 2 and 9 days after weaning

\begin{tabular}{|c|c|c|c|c|c|c|c|c|}
\hline & \multicolumn{4}{|c|}{ Days after weaning } & \multirow[b]{3}{*}{ s.e.d $d^{\dagger}$} & \multirow{2}{*}{\multicolumn{3}{|c|}{ Significance }} \\
\hline & \multicolumn{2}{|c|}{ Day 2} & \multicolumn{2}{|c|}{ Day 9} & & & & \\
\hline & NS & LS & NS & LS & & Treatment & Day & Interaction \\
\hline Protein & 140 & 155 & 131 & 133 & 12.8 & & & \\
\hline Trypsin & 35 & 57 & 60 & 73 & 5.74 & ** & $* *$ & \\
\hline Chymotrypsin & 1.8 & 2.5 & 1.6 & 1.6 & 0.40 & & * & \\
\hline
\end{tabular}

${ }^{\dagger}$ s.e.d. of treatment $\times$ day $(n=5)$.

and 9 post weaning in LS piglets. Whether this was a cause or effect of increased feed intake is uncertain. However in conclusion, there was no evidence that differences between LS and NS piglets in early post-weaning performance were related to development of the small intestine.

In the present experiment, accompanying the improved feed intake and weight gain of LS piglets after weaning were greater pancreatic trypsin activities on both days 2 and 9 post-weaning than in NS piglets. The development of pancreatic trypsin activity is related to ingestion of solid feed and increases markedly around weaning (Cranwell, 1995; Lalles et al., 2004); the increases in activity between days 2 and 9 in the present study concur with this. Pluske et al. (2003) found that in littermates who suckled the sow normally, lighter piglets had lower pancreatic trypsin activity at weaning and for the 14 days thereafter. In contrast in the present study, piglets that were lighter at weaning (because of reduced suckling) had greater pancreatic trypsin activities at both days 2 and 9 after weaning. The question arises therefore whether this difference arose from developmental differences, or from differences in feed intake post-weaning. All piglets were fasted prior to slaughter to reduce variation between piglets relating to when feed was last consumed, as trypsin secretion is related to feed intake. Mackink et al. (1994) showed that trypsin secretion was increased when piglet feed intake was reduced; since LS consumed more feed that NS piglets over the first 7 days post weaning, feed intake and fasting before slaughter were unlikely to be responsible for the difference between treatments. Since no piglets were slaughtered at weaning, the question also arises whether the differences in trypsin activity developed before weaning. In this context, Owsley et al. (1986) and Mackink et al. (1994) have both shown that trypsin activities change little in the first 4 days after weaning suggesting the differences in trypsin activity in the present experiment may have been established prior to weaning. Two possible explanations for increases in trypsin at weaning, other than the presence of solid feed in the gut, have been suggested by Pierzynowski et al. (1993) as the removal of milk from the diet, if constituents of milk suppress gut maturation, or the removal of the piglet from the sow. The milk restriction and separation of the LS piglets imposed at 14 days of age in the present experiment correspond to both the above suggestions but they cannot be separated. If these possible mechanisms do underlie the increased pancreatic trypsin activity in LS piglets then this increase in pancreatic trypsin may have facilitated the increased feed intakes of the LS piglets seen in the first 14 days post weaning and thus their superior performance at this time.

\section{Conclusion}

Piglets whose suckling was restricted in the absence of the confounding effects of either an enriched environment, a reduction in post-mixing aggression or any differences in creep feed intake, consumed more food and grew faster after weaning. Overall performance to 8 weeks of age was not different from counterparts whose suckling was not restricted. In the context of multi-suckling systems, this suggests that increased feed intake and growth post weaning may be a developmental difference induced by disrupted suckling. Further, the improvement may be related to enhanced digestive capacity in the form of increased pancreatic trypsin activity.

\section{Acknowledgements}

We thank former staff of the SAC Tillycorthie pig unit for help with animal management, and Morag Ewen for laboratory analyses. SAC receives financial support from the Scottish Executive Environment and Rural Affairs Department.

\section{References}

Algers B, Jensen P and Steinwall L 1990. Behaviour and weight changes at weaning and regrouping pigs in relation to teat quality. Applied Animal Behaviour Science 26, 143-155.

Appleby MC, Pajor EA and Fraser D 1991. Effect of management options on creep feeding by piglets. Animal Production 53, 361-366.

Beattie VE, Walker N and Sneddon IA 1995. Effect of past experience on later behaviour. In Proceeding of the 29th international congress of the International Society of Applied Ethology (ed. RM Rutter, J Rushen, HD Randle and JC Eddison), University Federation for Animal Welfare, London. Bøe K 1993. Maternal behaviour of lactating sows in a loose-housing system. Applied Animal Behaviour Science 35, 327-338.

Chapple RP, Cuaron JA and Easter RA 1989. Effect of glucocorticoids and limiting nursing on the carbohydrate digestive capacity and growth rate of piglets. Journal of Animal Science 67, 2956-2973.

Cranwell PD 1995. Development of the neonatal gut and enzyme systems. In The neonatal piglet: development and survival (ed. MA Varley), pp. 99-154. $C A B$ International, Wallingford. 
Erlanger BF, Eded F and Cooper AG 1966. The action of chymotrypsin on two new chromogenic substrates. Archives of Biochemistry and Biophysics 115, 206-210.

Erlanger BF, Kokowskey N and Cohen W 1961. The preparation and properties of two new chromogenic substrates of trypsin. Archives of Biochemistry and Biophysics 95, 271-278.

Glazer G and Sterr ML 1976. Requirements of activation of trypsinogen and chymotrypsinogen in rabbit pancreatic juice. Analytical Biochemistry 77, 131-140.

Hatet G, Edwards SA, Gall K and Arey DS 1994. Effect of three lactation housing systems on sow and piglet performance and behaviour. Animal Production 58, 475 (abstr.).

Hedemann MS, Højsgaard S and Jensen BB 2003. Small intestinal morphology and activity of intestinal peptidases in piglets around weaning. Journal of Animal Physiology and Animal Nutrition 87, 32-41.

Lalles JP, Boudry G, Favier C, Le Floc N, Luron I, Montagne L, Oswald IP, Pié S, Piel $S$ and Sevè B 2004. Gut function and dysfunction in young pigs' physiology. Animal Research 53, 310-316.

Lawes Agriculture Trust 1988. Genstat 5. (version 1.3), reference manual. Clarendon Press, Oxford, UK.

Lowry OH, Rosebrough NJ, Farr AL and Randall RJ 1951. Protein measurement with folin phenol reagent. Journal of Biological Chemistry 193, 265-275.

Mackink CA, Berntsen PJM, op den Kamp BML, Kemp B and Verstegen MWA 1994. Gastric protein breakdown and pancreatic enzyme activities in response to two different dietary protein sources in newly weaned piglets. Journal of Animal Science 72, 2843-2850.

Maroux S, Louvard D and Baratti J 1973. The aminopeptidase from hog-intestinal brush border. Biochimica Biophysica Acta 321, 282-295.

Messer M and Dahlqvist A 1966. A one-step ultramicro method for the assay of intestinal disaccharidases. Analytical Biochemistry 14, 376-392.
Nitsan Z and Liener I 1976. Enzymic activities in pancreas, digestive tract and feces of rat fed raw or heated soy flour. Journal of Nutrition 106, 300-305.

Owsley WF, Orr DE Jr and Tribble LF 1986. Effects of age and diet on the development of the pancreas and the synthesis and secretion of pancreatic enzymes in the young pig. Journal of Animal Science 63, 497-504.

Pierzynowski SG, Westrøm BR, Erlanson-Albertsson C, Ahre'n B, Svendsen J and Karlsson BW 1993. Induction of exocrine pancreas maturation at weaning in young developing pigs. Journal of Pediatric Gastroenterology and Nutrition $16,287-293$.

Pluske JR, Kerton DJ, Cranwell PD, Cambell RG, Mullan BP, King KH, Power GN, Pierzynowski SG, Westrom B, Rippe C, Peulen 0 and Dunshea FR 2003. Age, sex and weight at weaning influence organ weight and gastrointestinal development of weaning pigs. Australian Journal of Agricultural Research 54, 515-527.

Rantzer D, Svendsen J and Weström B 1995a. Weaning of pigs raised in sow-controlled and in conventional housing system: 1 . Description of systems, production and bacteriology. Swedish Journal of Agricultural Research 25, 37-46.

Rantzer D, Svendsen J and Weström B 1995. Weaning of pigs raised in sowcontrolled and in conventional housing system: 2 . Behaviour studies and cortisol levels. Swedish Journal of Agricultural Research 25, 61-71.

Thompson LH, Hanford KJ and Jensen AH 1981. Estrus and fertility in lactating sows and piglet performance as influenced by limited nursing. Journal of Animal Science 53, 1419-1423.

Wattanakul W, Sinclair AG, Stewart AH, Edwards SA and English PR 1997a. Performance and behaviour of lactating sows and piglets in crate and multisuckling systems; a study involving European White and Manor Meishan genotypes. Animal Science 64, 339-349.

Wattanakul W, Stewart AH, Edwards SA and English PR 1997b. Effect of grouping and changing sow location on suckling behaviour and performance. Applied Animal Behaviour Science 55, 21-35. 